\title{
Three-Dimensional Physical Modeling on Perforated Skirt Breakwater
}

\author{
Harman Ajiwibowo ${ }^{\# 1}$ \\ \# Ocean Engineering Department, Institut Teknologi Bandung, \\ Jalan Ganesa 10, Bandung 40132, Indonesia \\ ${ }^{1}$ harman.ajiwibowo17@gmail.com
}

\begin{abstract}
BP Tangguh has port facilities in Bintuni Bay, West Papua. The water depth ranges from 6 $\mathrm{m}$ to $9 \mathrm{~m}$. They plan to develop a new port basin area behind the existing jetty. Operational ocean waves usually reach the proposed new port basin with a significantly high ocean wave, which may hamper port operations. It is proposed to develop a Perforated Skirt Breakwater (PSB), and 3D physical modeling of the proposed breakwater is conducted in a wave basin to determine its effectiveness against the environmental conditions at Bintuni Bay. The effectiveness of a breakwater can be measured by quantifying the transmission coefficient $K_{T}$. The scaling of the models applies the principle of Froude similarity. The basin is equipped with 4 resistance-type wave probes and an 8-channel DAS (Data Acquisition System). Wave heights and periods data are observed. The incident and transmitted wave heights, before and after the PSB, are measured and processed. The relationships between $K_{T}$ and nondimensional variables are analyzed. The numerical model using a steady wave-action balance equation is also used to predict the wave transformation. A comparison with similar physical models in a $2 \mathrm{D}$ wave flume is presented.
\end{abstract}

Keyword - Physical modeling, three-dimensional, non-dimensional variables, perforated skirt breakwater (PSB), transmission coefficient.

\section{INTRODUCTION}

This The LNG Exploration site at Bintuni Bay (Fig. 1) has a combined dock facility that is operated to allow berthing of ships to load LNG from the refinery site. Berthing activities require calm wave conditions. A Perforated Skirt Breakwater (PSB) is to be installed in a water depth of 6-9 $\mathrm{m}$, to protect the proposed port area. At this water depth, a conventional rubble mound breakwater is costly. A PSB is a perforated skirt attached to a pile/column steel frame/foundation. There are layers of skirt, and chambers in between. Fig. 1 shows the application of a PSB in Singapore. Fig. 2a shows the location of Bintuni Bay. Fig. 2b shows the layout of the existing jetty and the area proposed for development.

The effectiveness of the breakwater depends on the transmission coefficient $K_{T}$, which is influenced by several physical parameters, such as the skirts of the breakwater (which affect the draft of the breakwater (S) and the length of the chamber $\left(L_{c}\right)$. The smaller the coefficient, the better the performance of the breakwater.

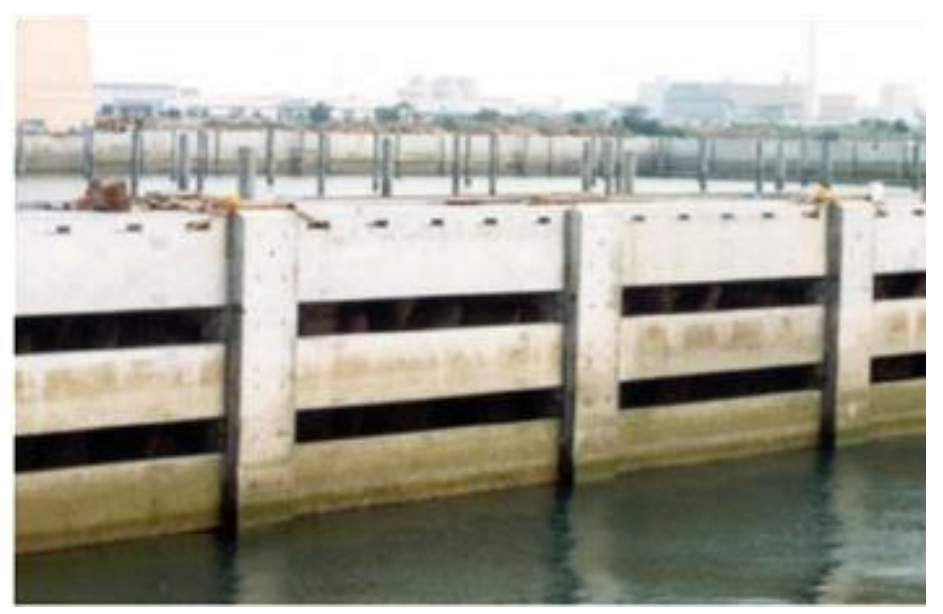

Fig. 1. PSB in Raffles Marina Singapore [1]. 


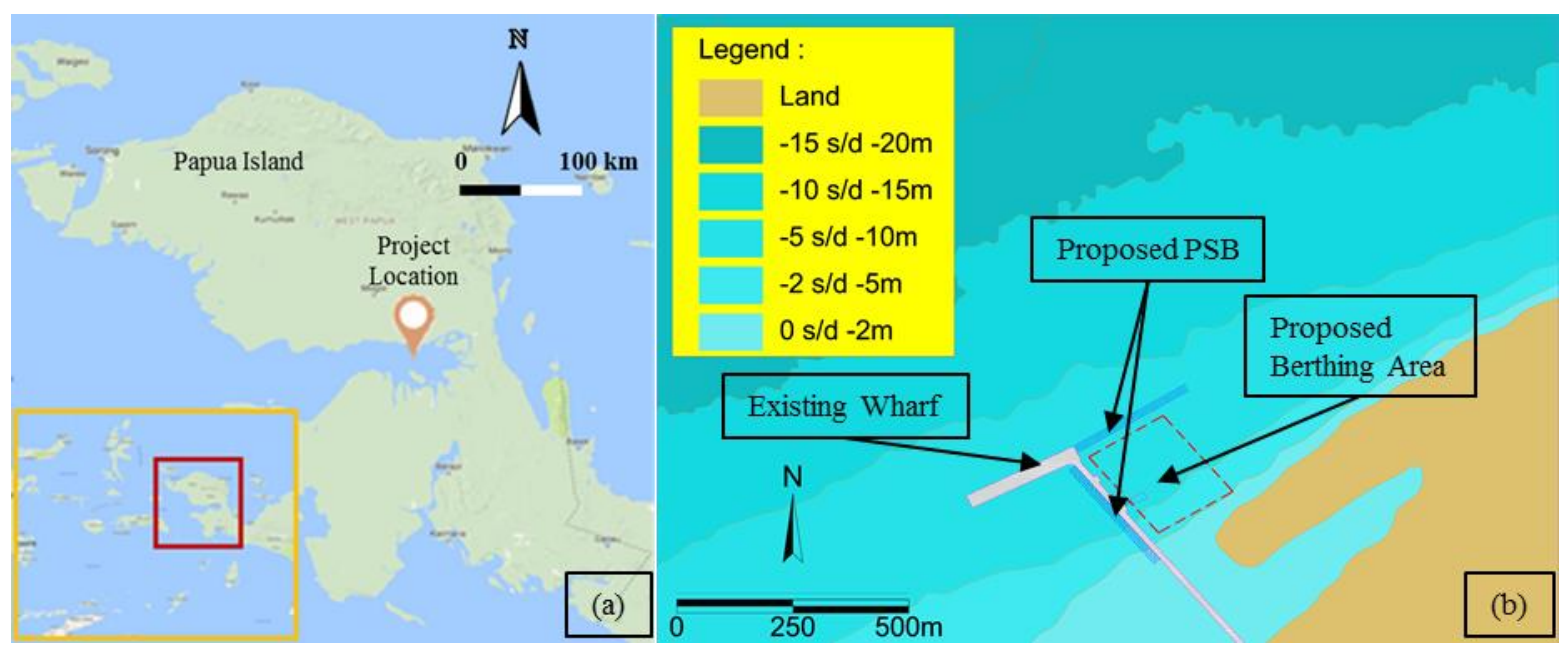

Fig. 2. (a) Project location at Bintuni Bay, West Papua, Indonesia and the layout of existing condition and the proposed PSB.

A perforated-wall caisson breakwater was first proposed by Jarlan in 1961 [2]. The perforated-wall breakwater consists of an empty or partially-filled chamber between a perforated front wall and an impermeable rear wall. Since the efficiency of this type of breakwater with respect to wave reflection and energy dissipation in front of the structure was first proved by laboratory experimental results, many researchers have proposed different designs for perforated-wall structures. Boivin (1964) tried to measure wave heights near the front of the perforated-wall caisson breakwater and proved the reduction of wave reflection by the structure [3].

Huang et al. (2011) examined many previous studies on the hydrodynamics of different types of perforated or slotted structures and reviewed the analytical, numerical, and physical model studies in terms of the wave reflection, transmission, and force [4]. They also discussed the numerical model results of the previous research work on a fully perforated breakwater, a partially perforated breakwater, a breakwater with multiple perforated walls, a perforated breakwater with a top cover, a perforated breakwater with a rock core, and a perforated breakwater with a horizontal porous plate, in terms of the wave reflection, the wave transmission, and the wave forces on the structures.

These kinds of perforated structures are typically used in Eastern Asia, as in Korea, China, and Japan. Lee, Jong-In et al. (2014) present the wave height distribution in terms of stem wave evolution phenomena on partially perforated wall structures through 3D laboratory experiments [5]. Tests were conducted by changing the relative chamber width. The results show that a larger relative chamber width reduces the wave energy more than a smaller one does within the range of the chamber width in the present study.

However, from the point of view of wave randomness, there is no major difference of wave height variations between monochromatic and random waves, regardless of the chamber width, the wave condition, and the incident wave angle. Ajiwibowo (2011) and Wurjanto (2010) conducted 2D physical modeling in a 2D wave flume with 3 chambers and an alternating skirt gap in each chamber's barriers [6-7]. The transmitted coefficients are quantified in terms of the relative water depth, wave steepness, and skirt draft.

\section{STUdy Location}

All A 3D model was developed and tested in a Wave Research Laboratory (WRL) under the Ministry of Public Works and Housing. The facilities of the WRL are as follows:

1. The wave basin is $30 \mathrm{~m}$ long, $20 \mathrm{~m}$ wide and $1 \mathrm{~m}$ deep (see Fig. 3);

2. A wave maker of piston-type that can generate monochromatic waves;

3. Resistance-type wave gauges;

4. An 8-channel Data Acquisition System (DAS). 


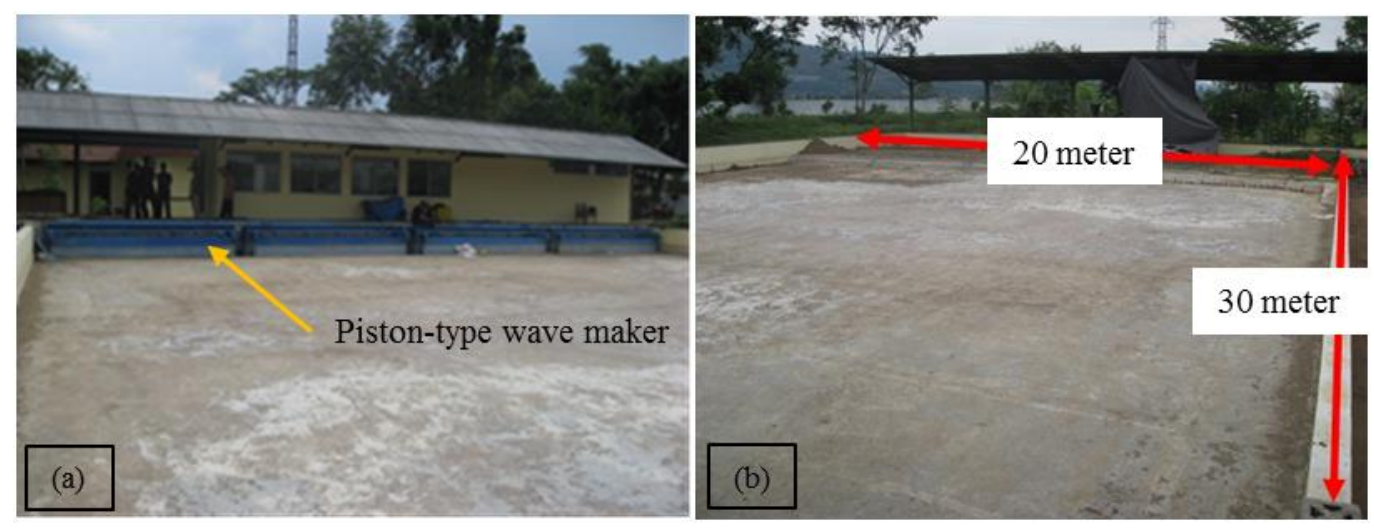

Fig. 3. (a) Wave maker and (b) wave basin at the WRL.

\section{III.MATERIAL, MODEL, AND METHOD}

All A 3D model was developed and tested in a Wave Research Laboratory (WRL) under the Ministry of Public Works and Housing. The facilities of the WRL are as follows:

\section{A. Material}

The model is made of wood.

\section{B. Model}

The PSB uses piles to support the upper structure. At the upper structure (around the water surface), there are some important parts that distinguish the PSB from other types of breakwater. These are skirts, chambers, and portals. The draft of the breakwater $S$ is the distance from the surface of the water to the bottom part of the skirts (see Fig. 4).

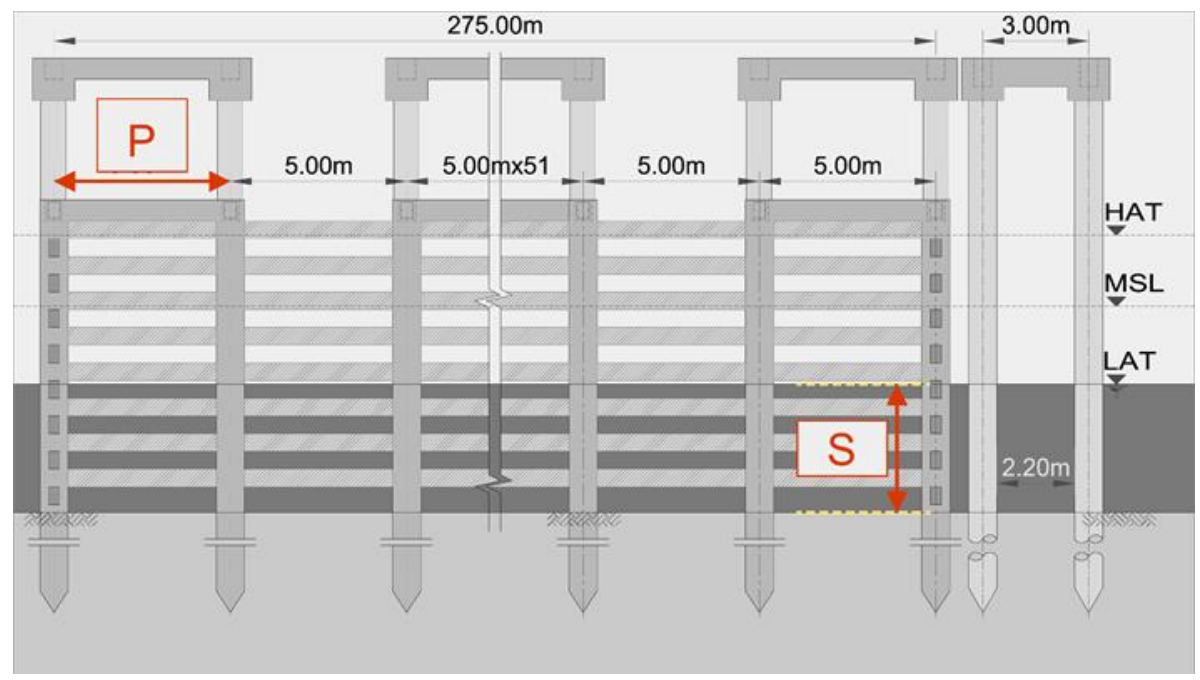

Fig. 4. Illustration of PSB (front view).

The skirts, chambers, portals and several parameters of the PSB are illustrated in Figs. 5 and 6. Definition of the chamber and portal can be seen in Fig. 5. The distance between piles is also shown. Fig. 4 shows that the total breakwater length is $275 \mathrm{~m}$, and Fig. 5 shows that the length of chamber $L_{c}=5 \mathrm{~m}$, so the total breakwater width B is $15 \mathrm{~m}$. The PSB has several filtering portals with skirts at each portal (see Fig. 5). The position of each skirt is alternating between the adjacent filtering portals to improve the effectiveness of the breakwater. 


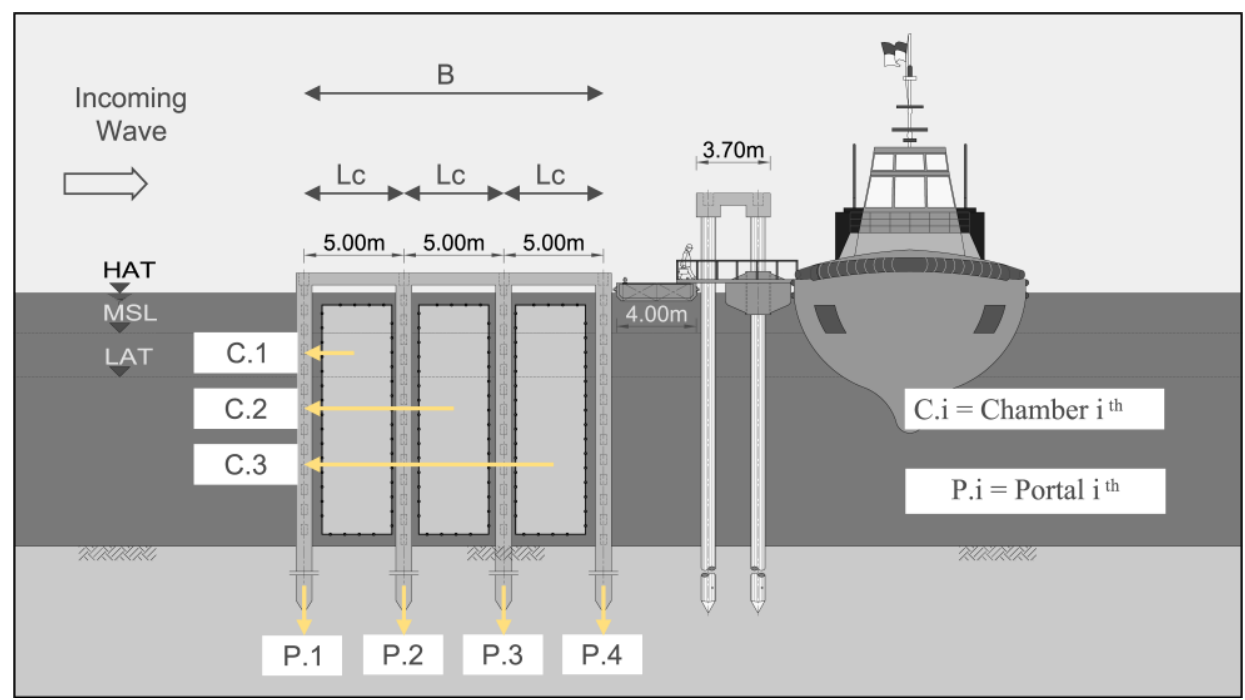

Fig. 5. Illustration of PSB (side view).

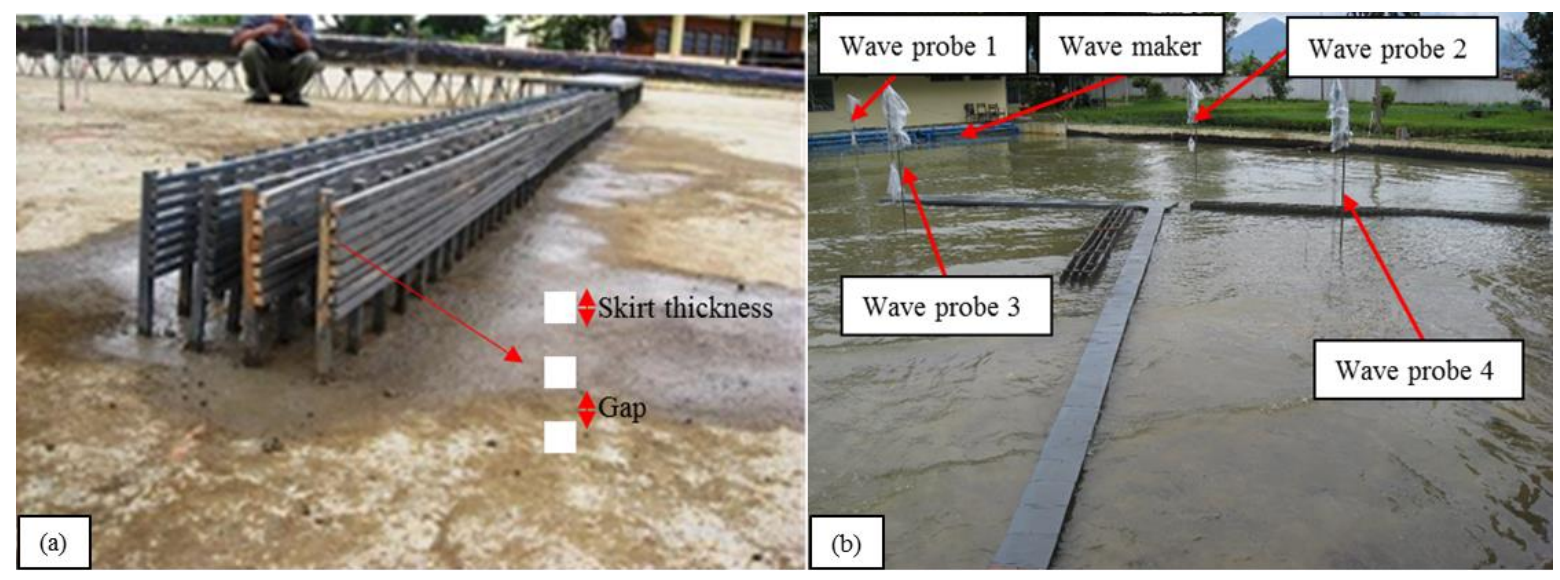

Fig. 6. (a) The sketch of skirts on PSB and (b) the position of wave probes in 3D wave basin.

The impermeable part of the skirts (P1) in the second filtering portal covers the perforated part of the skirts (P2) in the first filtering portal, so the position of the skirts on the first portal is the same as the third portal, while the position of the skirts on the second portal is the same as the fourth portal (see Fig. 5).

The prototype-model dimensions are presented in Table I. Tables II and III show the experiment's variable scenario for incoming waves from the West and North West, respectively. The environmental conditions are presented in Table II and Table III below.

TABLE I. Prototype-model dimensions

\begin{tabular}{cccc}
\hline Item & Symbol & Prototype (m) & Model (cm) \\
\hline Length of Chamber & $L_{c}$ & 5.0 & 10.0 \\
Total of Breakwater Width & $B$ & 15.0 & 30.0 \\
Total of Breakwater Length & $L$ & 275.0 & 550.0 \\
Number of Chambers & $N_{C}$ & 3 (no dimension) & 3 (no dimension) \\
Draft of Breakwater (relative to LAT ${ }^{* 1}$ ) & $S$ & 4.0 & 8.0 \\
Draft of Breakwater (relative to HAT ${ }^{* 2}$ ) & $S$ & 8.2 & 16.4 \\
Skirts Type 2 & $a$ & 0.7 & 1.4 \\
& $b$ & 0.3 & 0.6 \\
\hline
\end{tabular}

*1 LAT $=$ Lowest Astronomical Tide

${ }^{* 2} \mathrm{HAT}=$ Highest Astronomical Tide 
TABLE II. Scenario of experiments for incoming wave from West

\begin{tabular}{ccc}
\hline Variable & Prototype & Model \\
\hline Incident Wave Height & $1.5 \mathrm{~m}$ & $3.0 \mathrm{~cm}$ \\
$H_{i}$ & $2.6 \mathrm{~m}$ & $5.2 \mathrm{~cm}$ \\
& $4.0 \mathrm{~m}$ & $8.0 \mathrm{~cm}$ \\
Wave Period $T$ & $20.5 \mathrm{~s}$ & $2.9 \mathrm{~s}$ \\
& $14.8 \mathrm{~s}$ & $2.1 \mathrm{~s}$ \\
& $8.5 \mathrm{~s}$ & $1.2 \mathrm{~s}$ \\
\hline
\end{tabular}

TABLE III. Scenario of experiments for incoming wave from North West

\begin{tabular}{ccc}
\hline Variable & Prototype & Model \\
\hline Incident Wave Height & $1.5 \mathrm{~m}$ & $3.0 \mathrm{~cm}$ \\
$H_{i}$ & $2.6 \mathrm{~m}$ & $5.2 \mathrm{~cm}$ \\
& $4.0 \mathrm{~m}$ & $8.0 \mathrm{~cm}$ \\
Wave Period $T$ & $29.7 \mathrm{~s}$ & $4.2 \mathrm{~s}$ \\
& $17.0 \mathrm{~s}$ & $2.4 \mathrm{~s}$ \\
& $8.5 \mathrm{~s}$ & $1.2 \mathrm{~s}$ \\
\hline
\end{tabular}

\section{Scaling}

The scaling of the PSB model applies the principle of Froude similarity, where the scale and similarity model selection follow the Froude similarity defined as:

$$
\begin{aligned}
& \left(F_{r}\right)_{m}=\left(F_{r}\right)_{p} \\
& \left(\frac{v}{\sqrt{g L}}\right)_{m}=\left(\frac{v}{\sqrt{g L}}\right)_{p}
\end{aligned}
$$

where $v$ is the velocity of the fluid, $g=$ gravity acceleration, and $L$ is the characteristic length of the object inside the fluid. The length scale ratio is defined as $N_{L}=L_{p} / L_{m}$, where subscripts $m$ and $p$ denote the model and prototype, respectively. The determination of scaling was adjusted to the capacity of the wave basin. The scaling is determined to be 1:50. Steven Hughes using Froude similarity, the other scaling quantity, i.e. time scale and weight scale, can be written as Length Scale $=\mathrm{N}_{\mathrm{L}}=50$ [8]. Hughes (1993) states that the scaling for the short wave model for wave penetration to the ports is 1:50 to 1:150. Following Froude similarity, the time scale is found to be $1: \sqrt{N_{L}}(1: 7.07)$, and the weight scaling is $1: N_{L}^{3}(1: 125,000)$.

\section{Model Setup}

From analysis of the dominant wind data in Bintuni Bay, it is found that the dominant winds/waves come from the West and North-West direction. The setup of the model follows these two conditions: for incoming waves from the West and for incoming waves from the North-West. Models for incoming waves from West are given in Figs. 7a and 7c. While for incoming waves from North-West are given in Figs. 7b and 7d.

Besides the dominant winds and environmental conditions, the model also applies two breakwater position scenarios, called configuration 1 (cfg-1 as given in Figs. 7a and 7b) and configuration 2 (cfg-2 as given in Figs. $7 \mathrm{c}$ and $7 \mathrm{~d}$ ), in each direction of incoming waves. The water level at the basin is set to be at HAT. Four wave probes are placed in front of the wave maker, in front of the PSB in the north, inside the proposed port basin, and in front of the PSB in the west. Fig. $6 \mathrm{~b}$ shows the placement of the wave probes. 

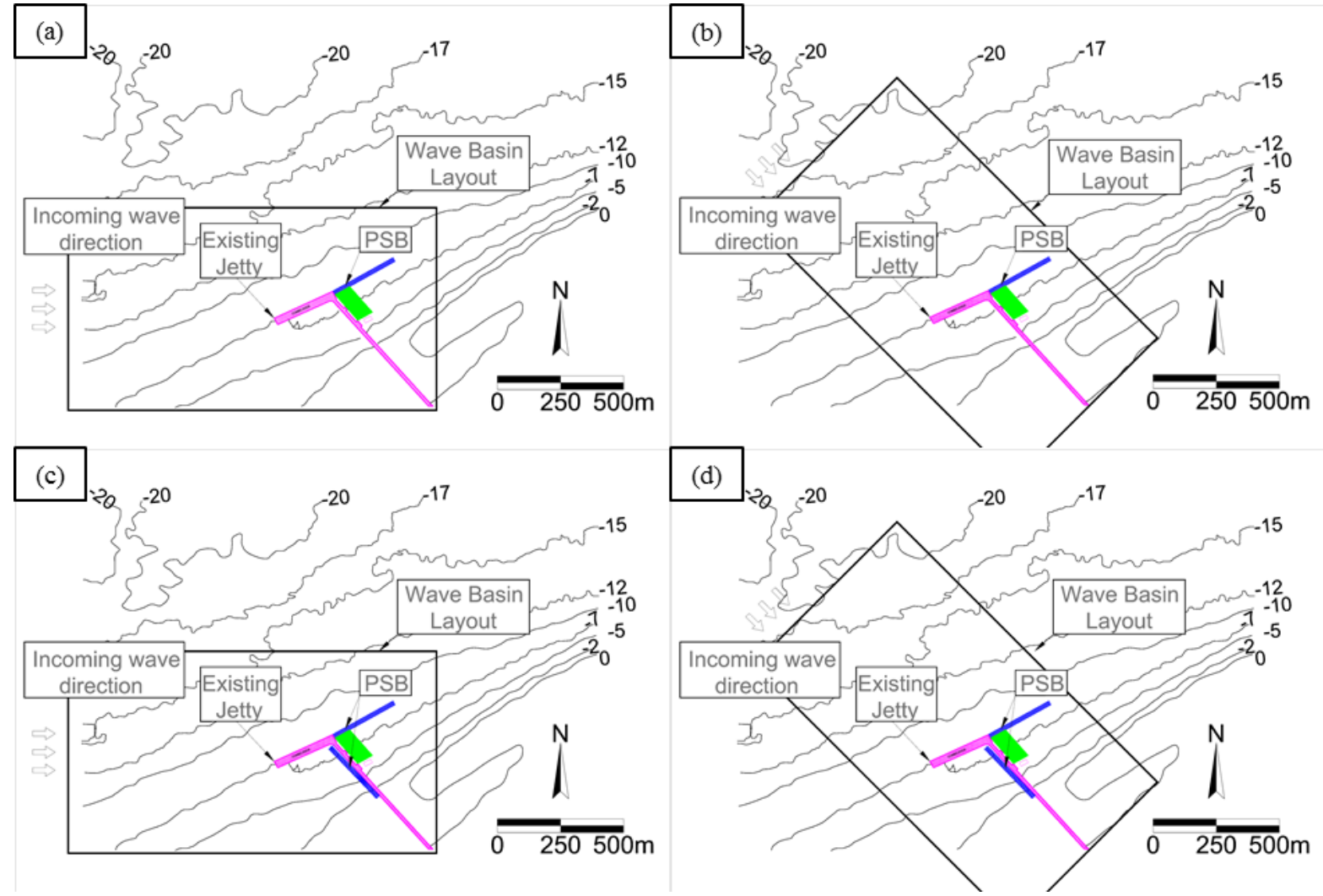

Fig. 7. Model setup with varying incoming wave directions and configurations. (a) cfg-1+West, (b) cfg-2+North-West, (c) cfg-1+West, and (d) cfg-2+North-West.

\section{E. Recording Wave Height $(H)$ and Period $(T)$}

Wave data are recorded using wave probes 1, 2, 3, and 4 (see Fig. 6b). Data from wave probe 2 are for the incident wave height $H_{i}$, and transmitted waves $H_{t}$ are considered to be from wave probe 4 . The procedure to record and process the wave data can be written as follows:

1. Extract recorded data from probe.

2. Carry out zero mean process.

3. Up-crossing the time series to get the wave heights and periods.

4. Then obtain the average incident wave heights $\overline{H_{i}}$ and transmitted wave height $\overline{H_{t}}$ for the time series wave heights in step 3.

Since monochromatic waves are used, the transmission coefficient $K_{T}$ can be written in terms of the averaged wave heights as follows:

$K_{T}=\frac{\overline{H_{t}}}{\overline{H_{i}}}$

Figs. $8 \mathrm{a}$ and $8 \mathrm{~b}$ show the cfg- 1 and cfg- 2 experiments. The inner side of the existing jetty is the proposed port basin to be protected. 

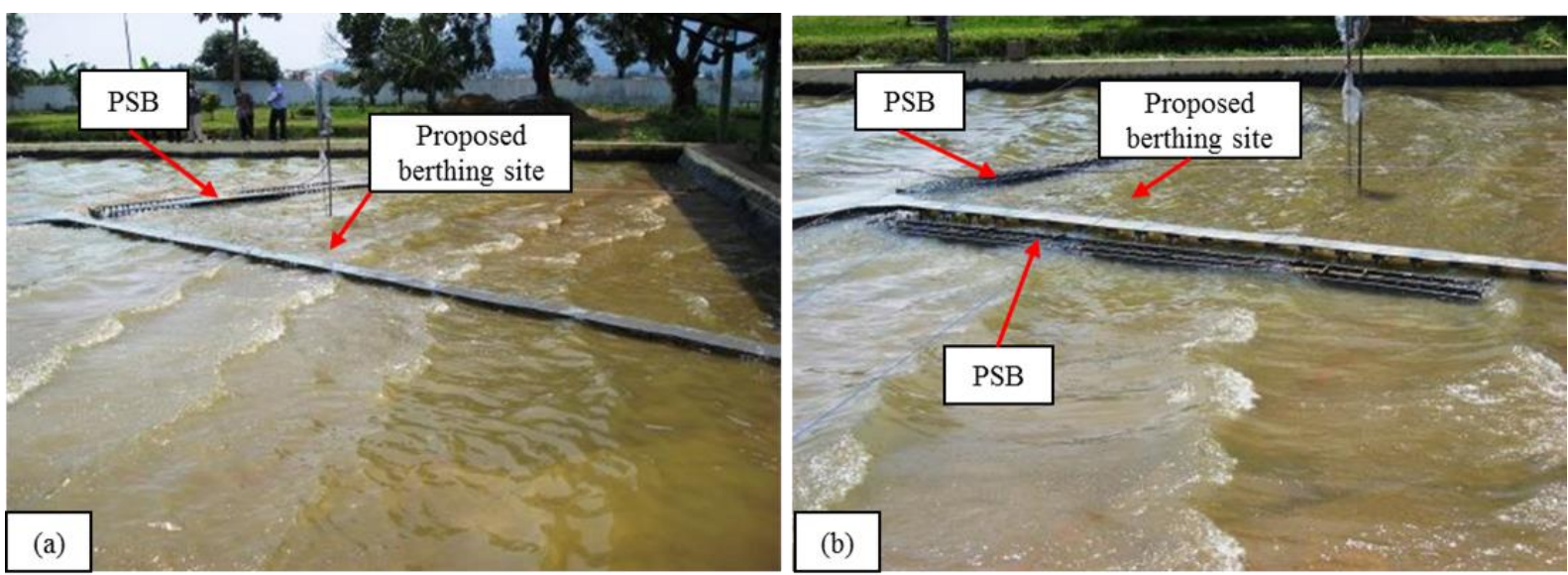

Fig. 8. Example of running data for (a) cfg-1 and (b) cfg-2.

\section{IV.DIMENSIONAL ANALYSIS}

Dimensional analysis is carried out in order to obtain non-dimensional parameters to be observed. The resulting non-dimensional parameters can be written as follows:

$$
K_{T}=f\left(\frac{H_{i}}{g T^{2}}, \frac{h}{H_{i}}, \frac{S}{H_{i}}, \frac{L_{c}}{H_{i}}, \frac{b}{H_{i}}\right)
$$

Eq. (4) is modified to be

$$
K_{T}=f\left(\frac{H_{i}}{L}, k h, \frac{S}{H_{i}}, \frac{L_{c}}{L}, \frac{b}{H_{i}}\right)
$$

where $L$ is the wavelength, and $k$ is the wave number.

\section{NUMERICAL MODEL}

A numerical model using the finite difference method to solve the wave energy balance equation (Mase, 2001) is used with the Coastal Modeling System (CMS) [9]. The governing equation of the model is written in Equation (6) below:

$$
\frac{\partial\left(c_{x} N\right)}{\partial x}+\frac{\partial\left(c_{y} N\right)}{\partial y}+\frac{\partial\left(c_{\theta} N\right)}{\partial \theta}=-\varepsilon_{b} N-S+\frac{\kappa}{2 \sigma}\left[\left(c c_{g} \cos ^{2} \theta N_{y}\right)_{y}-\frac{c c_{g}}{2} \cos ^{2} \theta N_{y y}\right]
$$

where $N=E(\sigma, \theta) / \sigma$ is the wave-action density to be solved and is a function of frequency $\sigma$ and direction $\theta . E(\sigma, \theta)$ is the spectral wave density representing the wave energy per unit water-surface area per frequency interval. $c$ and $c_{g}$ are the wave celerity and group velocity, respectively. $x$ and $y$ are the horizontal coordinates; $c_{x}, c_{y}$, and $c_{\theta}$ are the characteristic velocity with respect to $x, y$, and $\theta$, respectively. $N_{y}$ and $N_{y y}$ are the first and second derivatives of $N$ with respect to $y . \kappa$ is the empirical parameter of the intensity of the diffraction effect. $\varepsilon_{b}$ is the parameter of wave-breaking energy dissipation. $S$ denotes any additional source and sink (e.g., wind forcing, bottom friction loss, etc.). In the presence of an ambient current, the wave-action density is conserved, whereas the spectral wave density is not [10-11]. Both wave diffraction and energy dissipation are included in Equation (6) above. Mase (2001) and Mase et al. (2005) describe the implementation of the numerical scheme using that equation $[9,12]$.

The domain of the model follows Fig. 7, with the corresponding input as written in Tables I, II, and III. Figs. 9 and 10 show the bathymetrical and structure input to the model. Figs. 11 and 12 show the examples of the model result. The numerical model result shows that the wave height decreases inside the port proposed area, thus transmission coefficient $K_{T}<1$. 


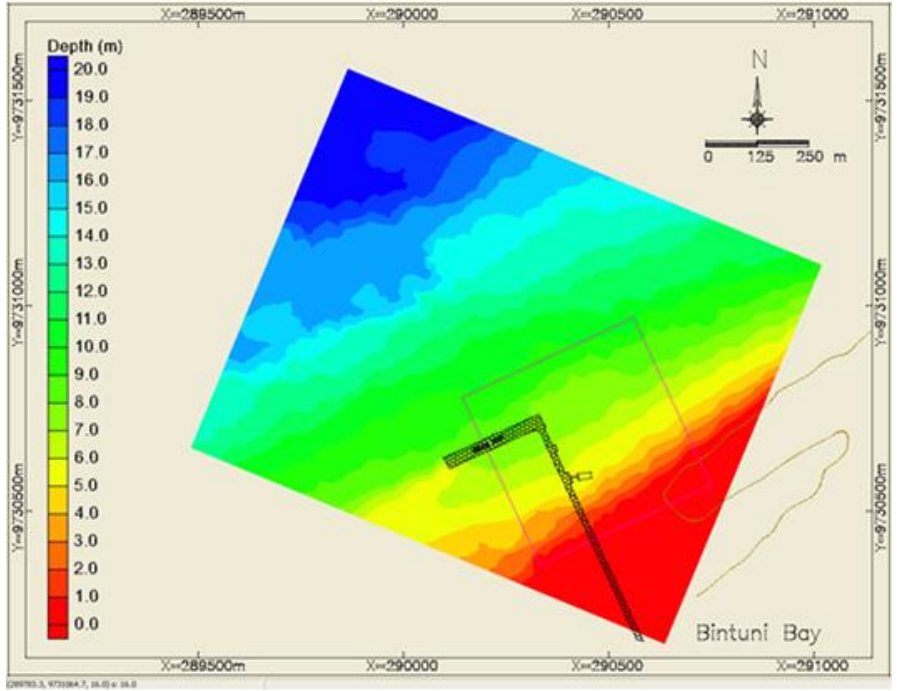

Fig. 9. Bathymetrical input to the model

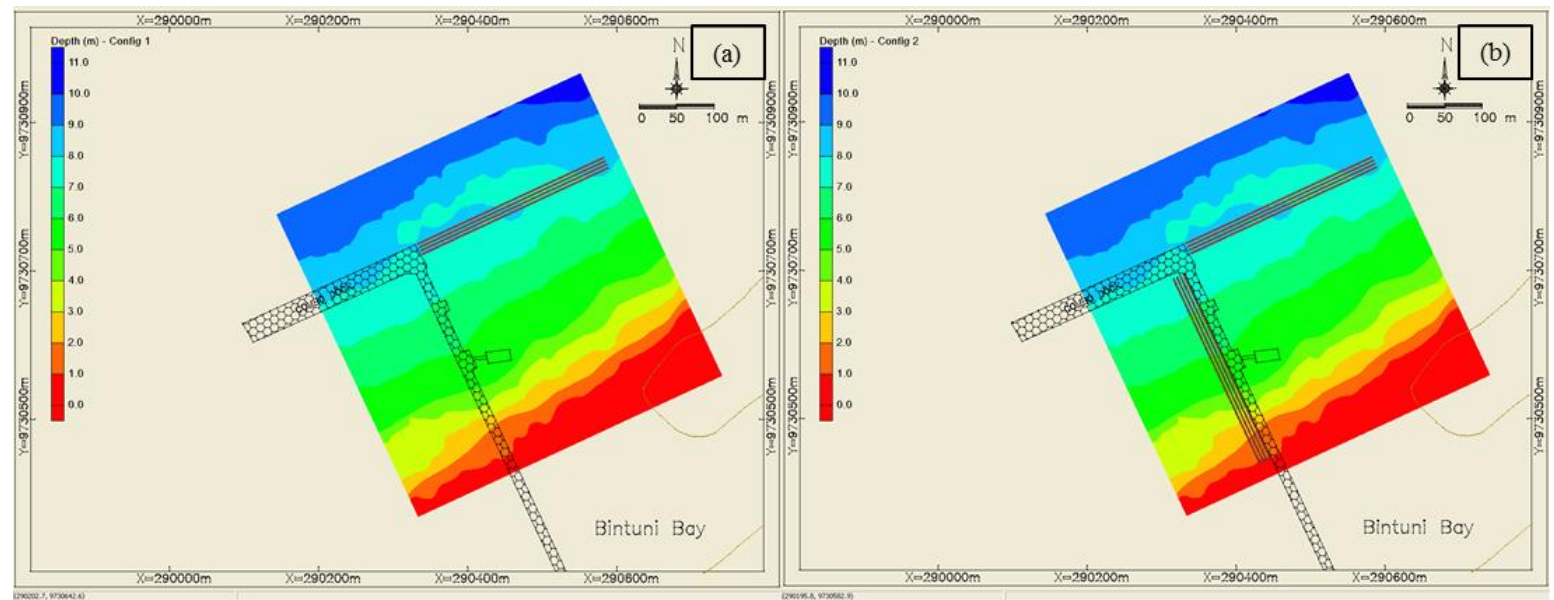

Fig. 10. Bathymetrical and structure input for (a) cfg-1 and (b) cfg-2
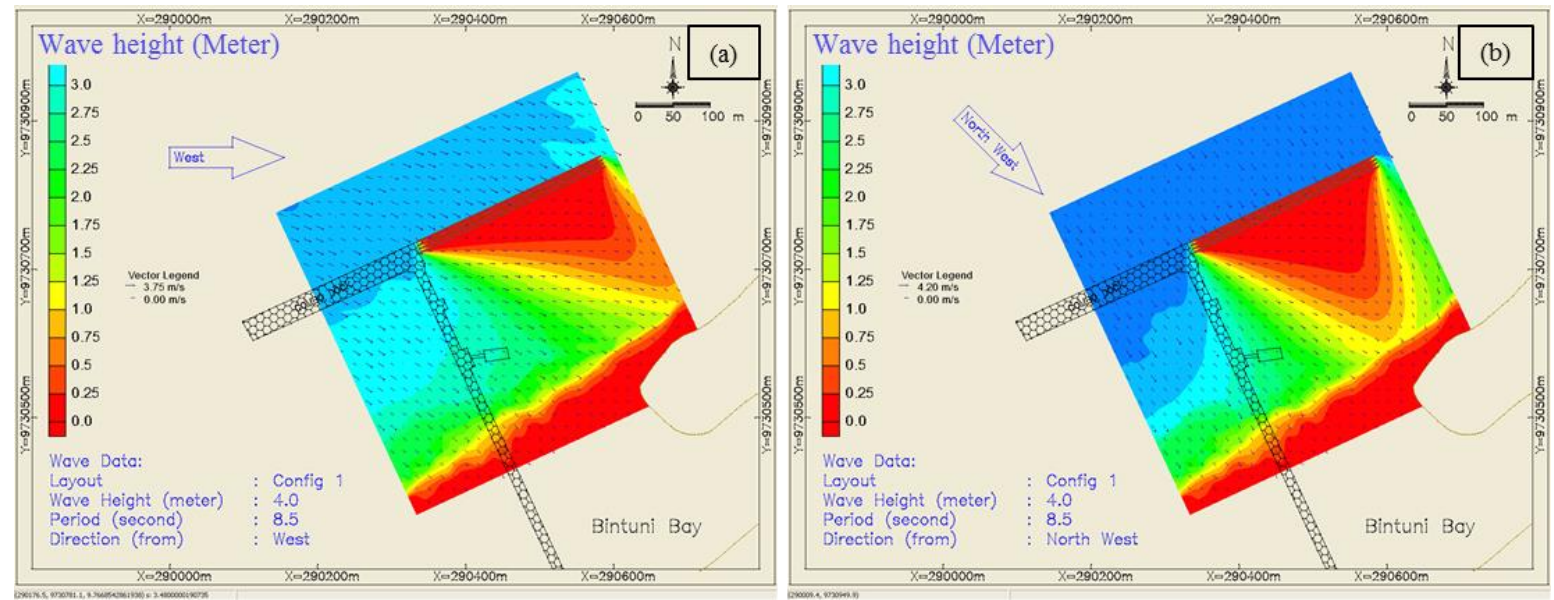

Fig. 11. Example of model result for cfg-1 for incoming waves from (a) West and (b) North-West. 

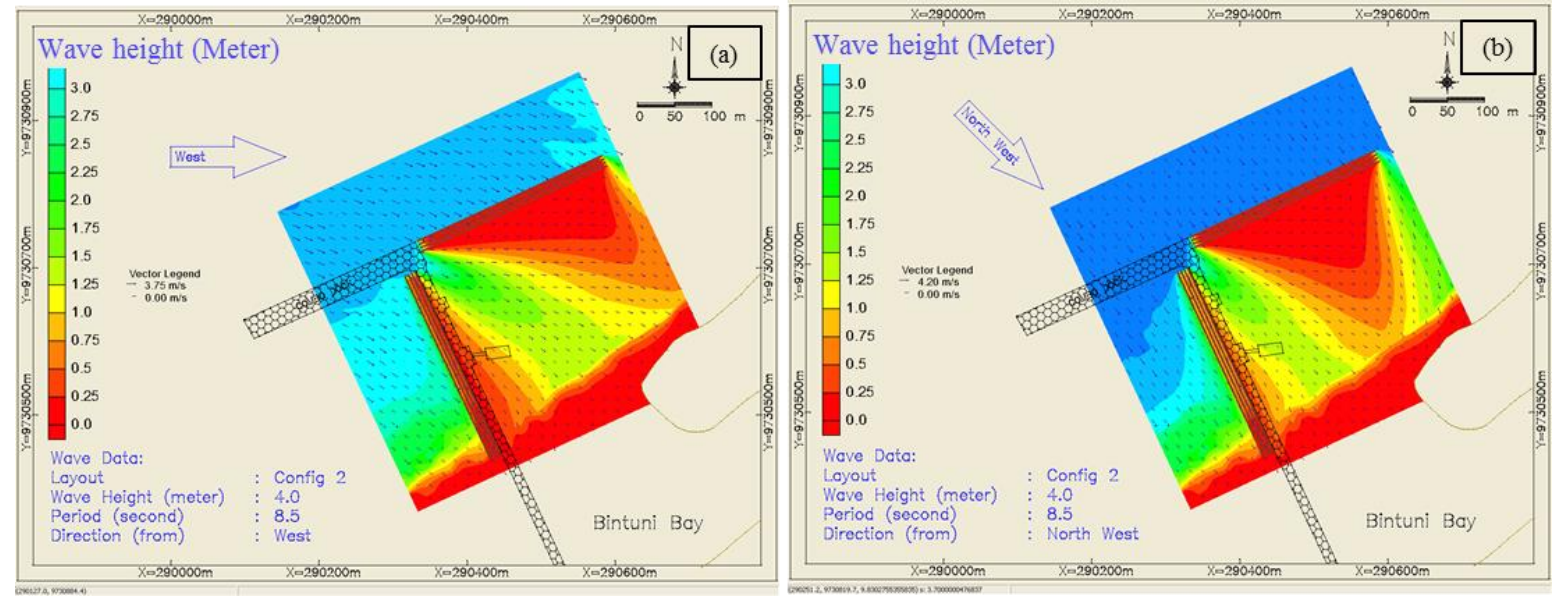

Fig. 12. Example of model result for cfg-2 for incoming waves from (a) West and (b) North-West.

Fig. 13 shows the location of the wave height data output to be used for the calculation of $K_{T}$. The $K_{T}$ is taken to be the wave height at point 4 divided by the wave height at point 2 . The numerical model is compared with the physical model, as seen in Figs. 14 to 16. In the spatial plot of the numerical model result, there are various wave heights within the proposed port area; thus the maximum and minimum values of the wave heights surrounding point 4 are plotted (see Fig. 13).

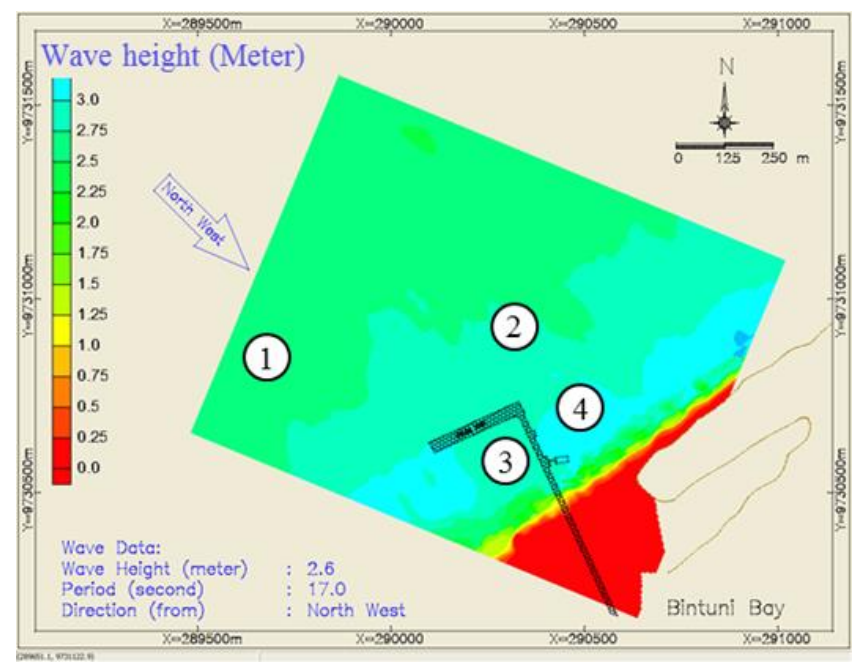

Fig. 13. Location of wave height data output for calculation.
口 WNW, cfg-1
$\Delta$ W, cfg-1
+ Predicted (Maximum)
$\diamond \mathrm{WNW}, \mathrm{cfg}-2$
$\mathbf{X} \mathrm{w}, \mathrm{cfg}-2$
* Predicted (Minimum)

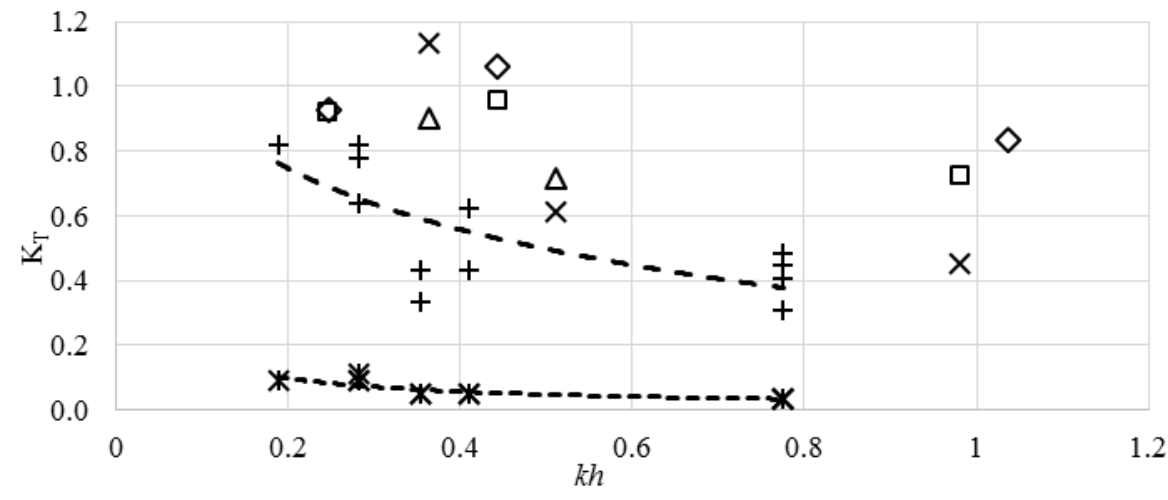

Fig. 14. Transmission coefficient $K_{T}$ in terms of water depth condition $k h$. 


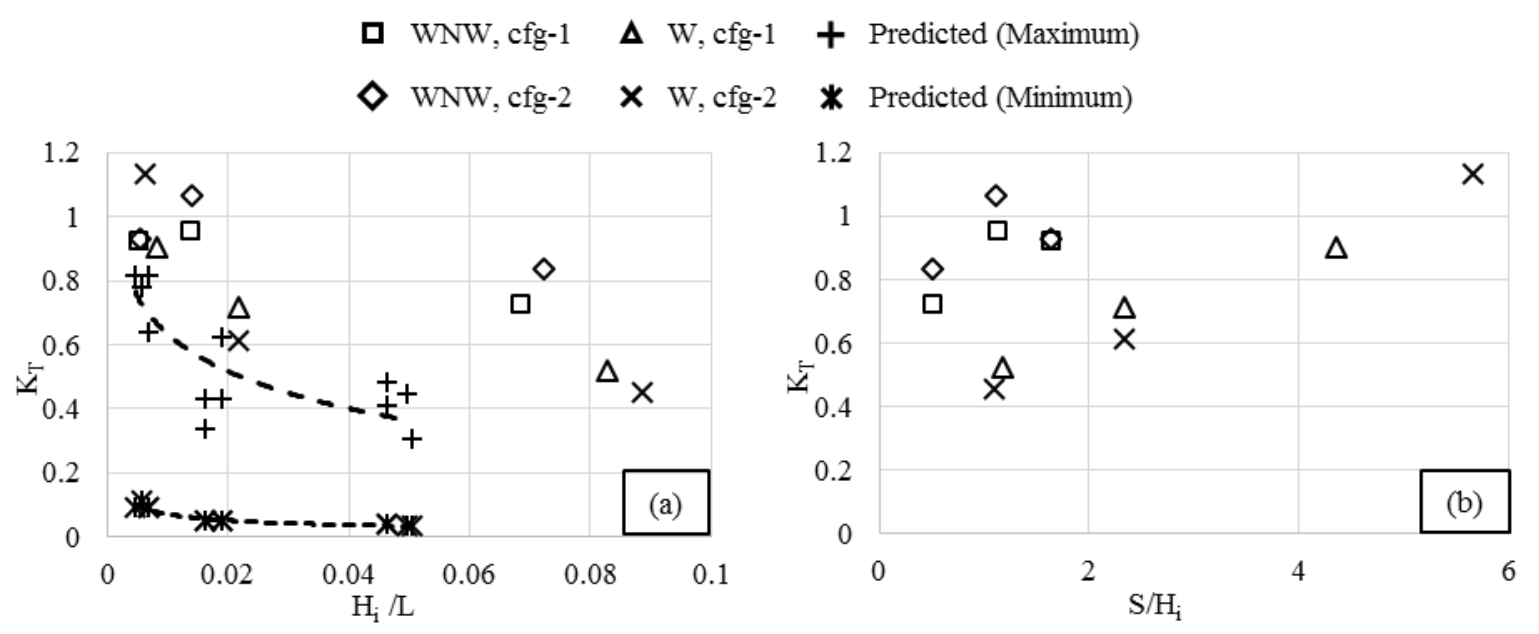

Fig. 15. Transmission coefficient $K_{T}$ in terms of (a) wave steepness $H_{i} / L$ and (b) wave steepness $S / H_{i}$.
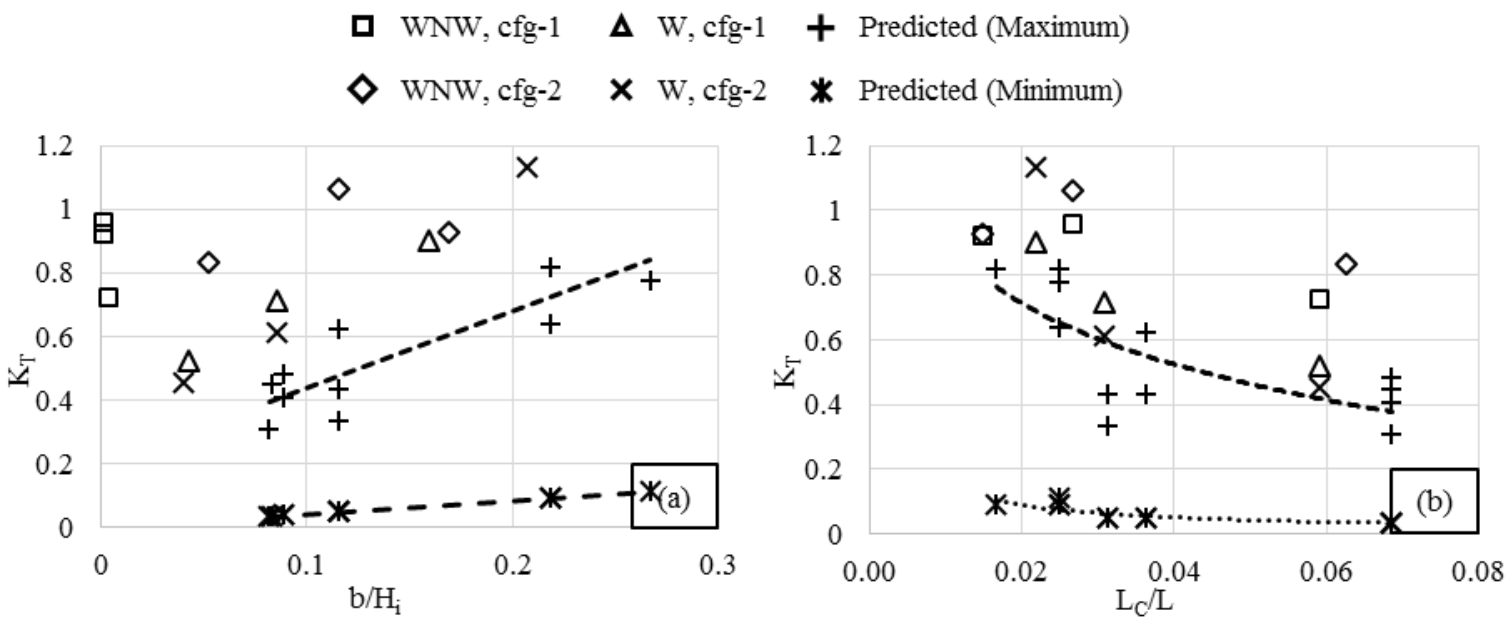

Fig. 16. Transmission coefficient $K_{T}$ in terms of (a) wave steepness $b / H_{i}$ and (b) width of chamber $L_{c} / L$.

\section{VI.RESULTS AND DISCUSSIONS}

A numerical model using the finite difference method to solve the wave energy balance equation (Mase, 2001) is used with the Coastal Modeling System (CMS) [9]. The governing equation of the model is written in Equation (6) below:

\section{A. Output}

To evaluate the optimal configuration, all the resulted transmitted coefficents of physical model $K_{T}$ are expressed in terms of $k h$ as seen in Fig. 14. For cfg-2 (PSB in both directions, see Figs. 7c and 7d), there is wave attenuation due to standing waves inside the proposed port area. This is a 3D effect which combines transmitted waves from the northern PSB and western side PSB. The placement of the second PSB in this case may cause higher waves inside the proposed port area. The values of $K_{T}$ are more than 1.0 near the boundary of $k h$ between the shallow and intermediate water depths. For $k h>0.5$ (intermediate water depth), the PSB performs well for all cfg-1 and cfg-2, denoted by values of $K_{T}$ between 0.4 and 0.8 . Cfg-2 provides larger values of $K_{T}$ for $k h$ between 0.3 (boundary of shallow water/intermediate water) and 0.45 . The predicted values show smaller values of $K_{T}$. Fig. 15a shows that the the greater the wave steepness $H_{i} / L$, the more effective the PSB is for all configurations, with $K_{T}$ between 0.42 and 0.8 for $H_{i} / L>0.02$.

At wave steepness $H_{i} / L<0.02$, the PSB does not perform well where $K_{T}>1$. The predicted values show smaller $K_{T}$ than the physical model. Generally, the predicted values are 20-30\% less than the physical modeling result. This would become important for engineers to note if relying on the numerical model in their design. Fig. $15 \mathrm{~b}$ shows the inconclusive result of the skirt draft effect on the $K_{T}$ values. It seems that the skirt gap and chambers length are more dominant parameters in wave energy dissipation in this type of breakwater, as seen in 
Fig. 16. As always, the second PSB in the West causes standing waves inside the port area denoted by $K_{T}>1$. For all plots, the predicted values show similar trends to the physical model, but the predicted values show smaller $K_{T}$ results. The smallest $K_{T}$ resulted from the physical model is found to be around 0.5 .

\section{B. Comparison with Other Physical Model Results}

Comparisons with published research experiment results on the PSB in a 2D wave flume are carried out. Ajiwibowo (2011) and Wurjanto et al. (2010) conducted 2D PSB experiments with monochromatic waves [6-7]. Fig. 17a shows the model inside the 2D flume at the ITB Ocean Engineering Wave Research Lab. Fig. 17b shows the definition sketch. For most of the experiments, the 2D and 3D experiments show good agreement in terms of wave steepness $H_{i} / L$, except for a smaller wave steepness $H_{i} / L<0.02$, where a $3 \mathrm{D}$ effect occurs, $K_{T}>1$ as seen in Fig. 15a.
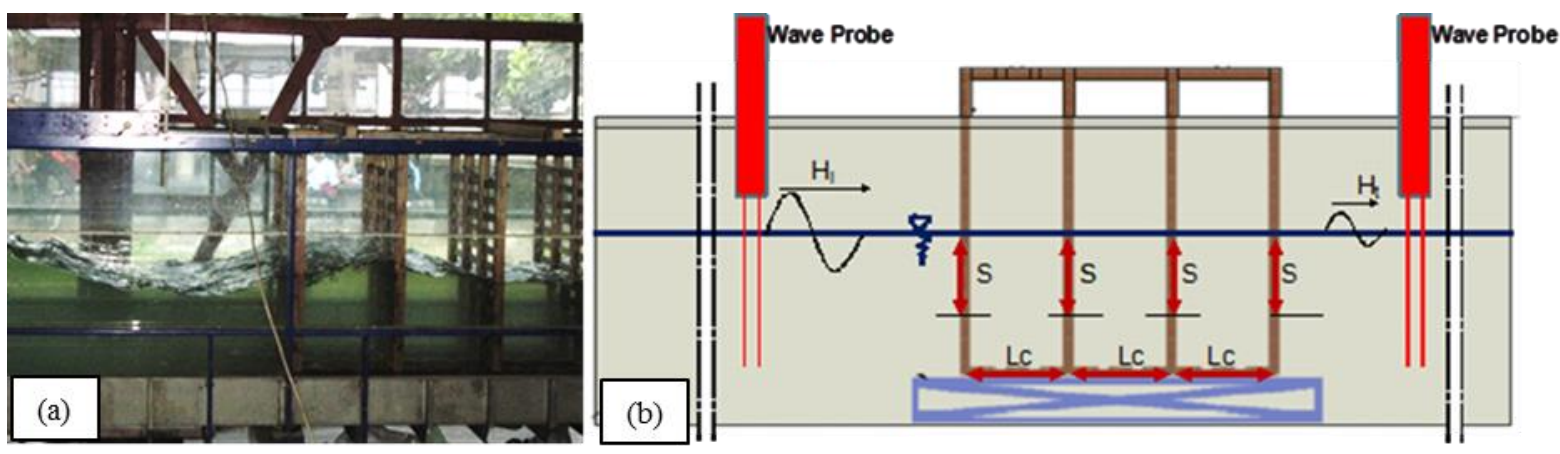

Fig. 17. (a) A two dimensional physical modeling on Perforated Skirt Breakwater (PSB) in Ocean Wave Research Laboratory, ITB and the definition sketch of the 2D PSB experiment [6-7].

The 2D experiments show the smallest $K_{T}$ of around 0.22 , while the 3D experiments show the smallest $K_{T}$ of 0.5. The 3D experiments show the effectiveness of the PSB more realistically than the $2 \mathrm{D}$ experiments. In Figs. 18 and 19, it can be seen that the smallest $K_{T}$ in the 3D experiments is 0.5 and it is found around $S / H_{i}=$ 1 , while in the $2 \mathrm{D}$ experiments the $K_{T}$ is found to be smaller (0.2) for $S / H_{i}$ around 2.

$$
\begin{array}{ll}
\boldsymbol{\square} \mathrm{NW}, \mathrm{cfg}-1 & \boldsymbol{\Delta} \mathrm{W}, \mathrm{cfg}-1 \\
\boldsymbol{\Delta} \mathrm{NW}, \mathrm{cfg}-2 & \mathbf{X} \text { W, cfg-2 }
\end{array} \text { + Wurjanto, A. et al. (2010), Ajiwibowo, H. (2011) }
$$

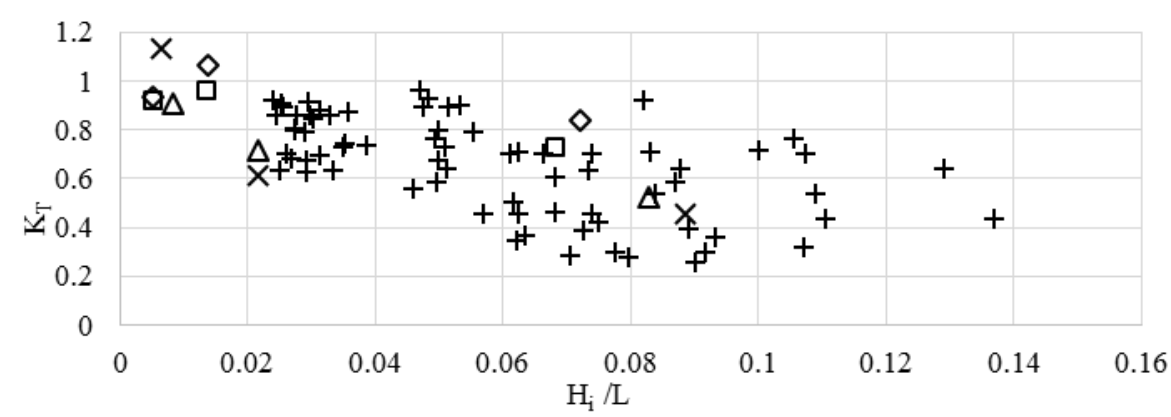

Fig. 18. Comparison of $K_{T}$ vs wave steepness $H_{i} / L$ for 3D PSB experiments and 2D PSB experiment result carried out by Wurjanto et al. (2010) for long waves [7] and Ajiwibowo (2011) for short waves [6] 

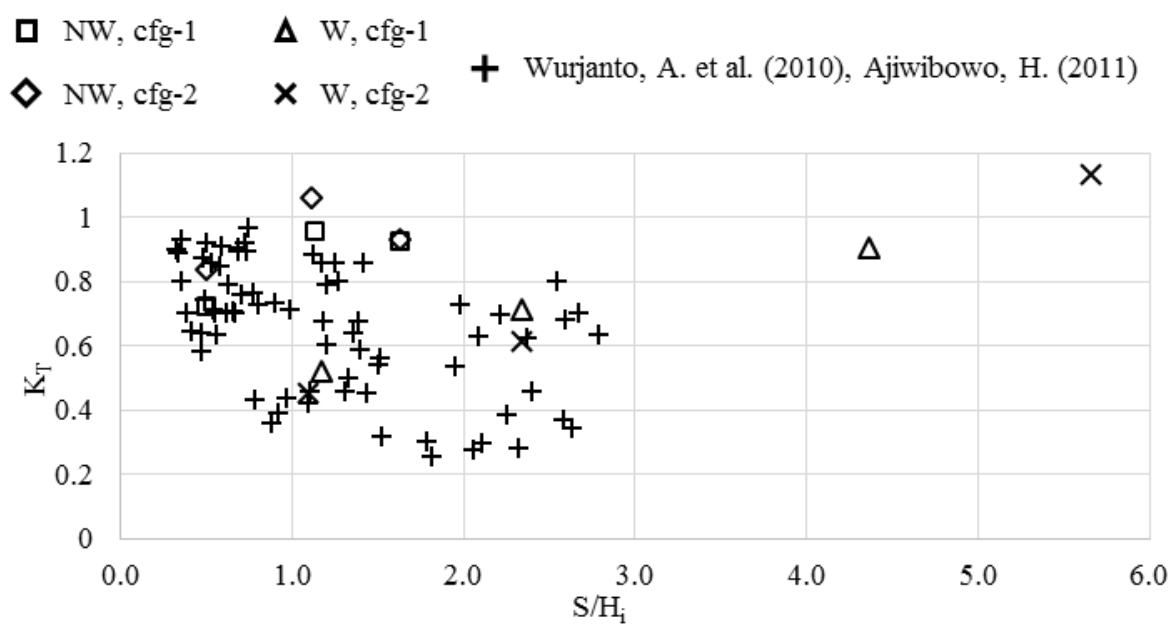

Fig. 19. Comparison of $K_{T}$ vs wave steepness $H_{i} / L$ for 3D PSB experiments and 2D PSB experiment results.

\section{CONCLUSION}

1. It can be concluded that the PSB is effective for a shorter wave period/higher wave steepness, but not effective for longer wave periods. For shorter waves, it can dampen the waves by up to $50 \%$.

2. Wave steepness, skirt gap, and chambers length are the dominant parameters in PSB effectiveness.

3. The physical model can show more realistic and dependable results, and should be used to validate any numerical model development.

4. The PSB on the western side is redundant, since its presence causes higher transmitted waves that result when two transmitted waves meet and form standing waves inside the proposed port

\section{ACKNOWLEDGMENT}

Author is thanking The British Petroleum of Indonesia for funding this research.

\section{REFERENCES}

[1] M. Bloxam, G. Maxted, and J. Murray, "Wave Energy Dissipating Wharf: Raffles Marina Breakwater, Singapore," Coasts \& Ports Australasian Conference No. 95, 2003.

[2] G. E. Jarlan, “A perforated vertical wall breakwater,” Dock and Harbour Authority, vol. 21 (486), pp. 394-398, 1961.

[3] R. Boivin, Comments on Vertical Breakwaters with Low Coefficients of Reflection. London, UK: The Dock and Harbour Authority, 1964.

[4] Z. Huang, Y. Li, and Y. Liu, "Hydraulic performance and wave loadings of perforated/slotted coastal structures: a review," Ocean Engineering, vol. 38 (10), pp. 1031-1053, 2011.

[5] J. I. Lee, S. Shin, "Experimental study on the wave reflection of partially perforated wall caissons with single and double chambers," Ocean Engineering, vol. 91, pp. 1-10, 2014.

[6] H. Ajiwibowo, "2D physical modeling to measure the effectiveness of perforated skirt breakwater for short-period waves," ITB Journal of Engineering Science, vol. 43 (1), pp. 57-78, 2011

[7] A. Wurjanto, H. Ajiwibowo, R. Zamzami, "Pemodelan Fisik 2-D untuk Mengukur Tingkat Efektivitas Perforated Skirt Breakwater pada Kategori Gelombang Panjang,” Jurnal Teoretis dan Terapan Bidang Rekayasa Sipil, vol. 17 (3), pp. 211-216, 2010.

[8] S. A. Hughes, Physical Models and Laboratory Techniques in Coastal Engineering. Singapore, Singapore: World Scientific Publishing, 1993.

[9] H. Mase, "Multidirectional random wave transformation model based on energy balance equation," Coastal Engineering Journal, vol. 43 (4), pp. 317-337, 2001.

[10] F. P. Bretherton, C. J. R. Garrett, "Wave trains in inhomogeneous moving media,” Proc. Roy. Soc. A, vol. 302, pp. 529-554, 1968.

[11] G. B. Whitham, Linear and Nonlinear Waves. New York, United States: John Wiley \& Sons, 1974.

[12] H. Mase, K. Oki, T. Hedges, and H. J. Li, "Extended energy-balance-equation wave model for multidirectional random wave transformation," Ocean Engineering, vol. 32, pp. 961-985, 2005.

\section{AUTHOR PROFILE}

H. Ajiwibowo's research interests are in physical and numerical modeling of water resources and ocean engineering. He graduated from the Civil Engineering Department, Bandung Institute of Technology in 1988 and continued to the Graduate Program in the same field at Oregon State University (OSU), Corvallis, Oregon, USA. He graduated from OSU in 2002. He is currently an Associate Professor at the Faculty of Civil and Environmental Engineering, Bandung Institute of Technology, Indonesia. 